\title{
Ultramicrofluorimetric determination of calcium in plasma
}

\author{
M. R. LEWIN, M. R. WILLS, AND D. N. BARON \\ From the Department of Chemical Pathology, Royal Free Hospital, London
}

SYNOPSIS A precise and reproducible method is described for the ultramicro fluorimetric deter mination of calcium in plasma, based upon the formation of a fluorescent complex between calcium and calcein at a strongly alkaline $p \mathrm{H}$.

In a group of normal subjects, the mean concentration of plasma calcium was $9.66 \mathrm{mg} / 100 \mathrm{~min}$ with a normal range of 8.9 to $10.4 \mathrm{mg} / 100 \mathrm{ml}$.

The accurate and precise estimation of calcium in serum and plasma is a complex and difficult problem. The classical oxalate precipitation method of Clark and Collip (1925) is still widely used, although technically tedious and not fully accurate. Many recent methods are based upon the method for complexometric titrations of metallic ions with EDTA of Schwarzenbach and Gysling (1949), and use visual endpoint indicators, including murexide (Carubelli, Smith, and Hammarsten, 1959), calcein (Baron and Bell, 1957), and Cal-red (Bachra, Dauer, and Sobel, 1958). We have found these titrimetric methods to be rapid but somewhat lacking in precision due to indistinct endpoints. Spectrophotometric determination of endpoints adds precision. Calcium estimation by flame photometry (Butterworth, 1957) and atomic absorption spectrophotometry (Thin and Thomson, 1967) require expensive instruments, and there are problems of ion interference.

Wallach and Steck (1963) described a fluorimetric technique for the micro-determination of calcium in biological materials using calcein, and Kepner and Hercules (1963) used this complexing compound for the determination of calcium in blood serum. Using the Kepner and Hercules technique, we found great difficulty in establishing reproducible calibration curves. We report here an investigation into the fluorimetric estimation of calcium with calcein, and describe the method that we have evolved for the routine ultramicro determination of calcium in blood plasma.

\section{MATERIALS AND METHOD}

APPARATUS The instrument used was a Locarte fluorimeter, model LF.4 mark II, with a mercury lamp. An Received for publication 25 July, 1968.
LF.3 filter was used on the primary (excitation) side corresponding to the $436 \mathrm{~m} \mu$ mercury line. On th secondary (emission) side, a wavelength of $517 \mathrm{~m} \mu$ was selected with a sharp cut-out filter LF.7, which transmites light only of wavelengths greater than $510 \mathrm{~m} \mu$. The excitation and emission maxima occur at 495 and $517 \mathrm{~m} \mu$ respectively. (We are indebted to Dr Peter Clark for the use of his Baird Atomic spectrofluorimeter in the measurement of these maxima.) At our working calcei concentration, exciting at wavelengths exceeding $436 \mathrm{m \&}$ on the Locarte fluorimeter results in a marked increase is fluorescence. At this high level of fluorescence, however quenching occurs by an 'inner filter' effect (Williams and Bridges, 1964), ie, quenching by the internal absorption of exciting and emitted radiations.

REAGENTS All the water used was steam-distilled and further purified by deionization using a mixed bed iog exchange column.

All glassware used to make up reagent solutions was allowed to stand in concentrated $\mathrm{HCl}$ (Analar reagen grade) for three days and then washed with at least 10 changes of deionized water. Glassware must be cared fof meticulously to avoid contamination.

Stock solution of calcein $(100 \mathrm{mg} / 100 \mathrm{ml})$ Calcei (fluorescein-complexone indicator, Hopkins and William $\overline{\bar{s}}$ batch no. 014151), $100 \mathrm{mg}$, was dissolved in $20 \mathrm{ml}$ of $0.6 \mathrm{~N} \mathrm{KOH}$ and then made up to $100.0 \mathrm{ml}$ with 0.6 $\mathrm{N} \mathrm{KOH}$ in a volumetric flask. This solution when storef in a polythene bottle, painted black, at $4^{\circ} \mathrm{C}$, was stable for six to eight weeks.

Working solution of calcein $(8 \mathrm{mg} / \mathrm{l}$.) Stock calcein solution, $8.0 \mathrm{ml}$, was diluted to $1.0 \mathrm{l}$. with $0.6 \mathrm{~N} \mathrm{KOF}$ This solution was stored in a polythene bottle at roop temperature and must be freshly prepared every sevem days.

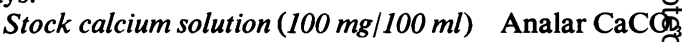
was dried to constant weight and $2.497 \mathrm{~g}$ dissolved $50 \mathrm{ml} 1.0 \mathrm{~N} \mathrm{HCl}$. This solution was made up to a finß volume of 1.01 . in a volumetric flask with deionized water. The solution was stored in a polythene bottle. 
Working calcium solutions These were prepared by diluting the stock calcium solution in water to give final concentrations over the range 4.0 to $12.0 \mathrm{mg} / 100 \mathrm{ml}$. Solutions were stored in polythene containers and freshly prepared weekly.

Artificial fluorescence standard This was prepared from an epoxy resin, Araldite A (Ciba A.R.L. Ltd, Duxford, Cambridge), The resin was warmed and run into a fluorimeter cuvette, care being taken to avoid air bubbles. The cuvette was then sealed.

METHOD The fluorimeter was switched on and allowed to stabilize for at least 15 minutes. A water bath set at $25^{\circ} \mathrm{C}$ contained a water blank, an artificial fluorescence standard, and a number of empty silica cuvettes, which were allowed to equilibrate for at least 10 minutes. The instrument was set at zero using the water blank. The artificial araldite standard was used as a standard reference source of fluorescence, with which the sensitivity of the fluorimeter was set. With the artificial standard at a scale deflection of 4 , the $12 \mathrm{mg} / 100 \mathrm{ml}$ calcium standard gave a full scale deflection of 14 . Working calcein solution, $5 \mathrm{ml}$, was pipetted into $10 \mathrm{ml}$ disposable polystyrene tubes (Stayne Laboratories Ltd, Bucks) and allowed to equilibrate in the water bath for 10 minutes. Then $20 \mu \mathrm{l}$ of standard or sample was added from a disposable capillary pipette (Dade Dispo capillary pipettes), the tip of which was wiped with a calcium-free filter paper (Whatman no. 42). Medical wipes should not be used as they contain highly fluorescent constituents which cause contamination. The tube was stoppered, shaken by inversion 15 times, the contents transferred to a temperature equilibrated cuvette, and the fluorescence intensity measured one minute after adding the fluorescent mixture to the cuvette. Both tests and standards were corrected for the fluorescence of the calcein solution at $25^{\circ} \mathrm{C}$. The concentration of calcium in the plasma was calculated from a standard calibration curve.

CAlibration CURve A typical calibration is shown in Figure 1. The curve is S-shaped due to the formation of both a mono- and a di-calcium complex (Wallach and Steck, 1963); the di-calcium complex forms the major fluorescent species. By careful adjustment of the calcein concentration, the linear section of the curve can be fixed to cover the range of calcium concentration required. In our laboratory, we have found that a calcein concentration of $8 \mathrm{mg} / 1$. gives a linear range over calcium concentrations of 4 to $14 \mathrm{mg} / 100 \mathrm{ml}$. By raising or lowering the calcein concentrations, linearity over a higher or lower range of calcium concentrations can be achieved. For every new batch of calcein purchased, the concentration required to give a linear calibration curve over the selected calcium range must be determined.

EFFECT OF TEMPERATURE The effect of temperature on fluorescence, using standard calcium solutions, is shown in Figure 2. At $25^{\circ} \mathrm{C}$, a temperature change of $\pm 1{ }^{\circ} \mathrm{C}$ on a $10 \mathrm{mg} / 100 \mathrm{ml}$ calcium standard, gave a $2 \%$ error. We selected $25^{\circ} \mathrm{C}$ as the working temperature as this is near our normal ambient temperature, and thus minimizes

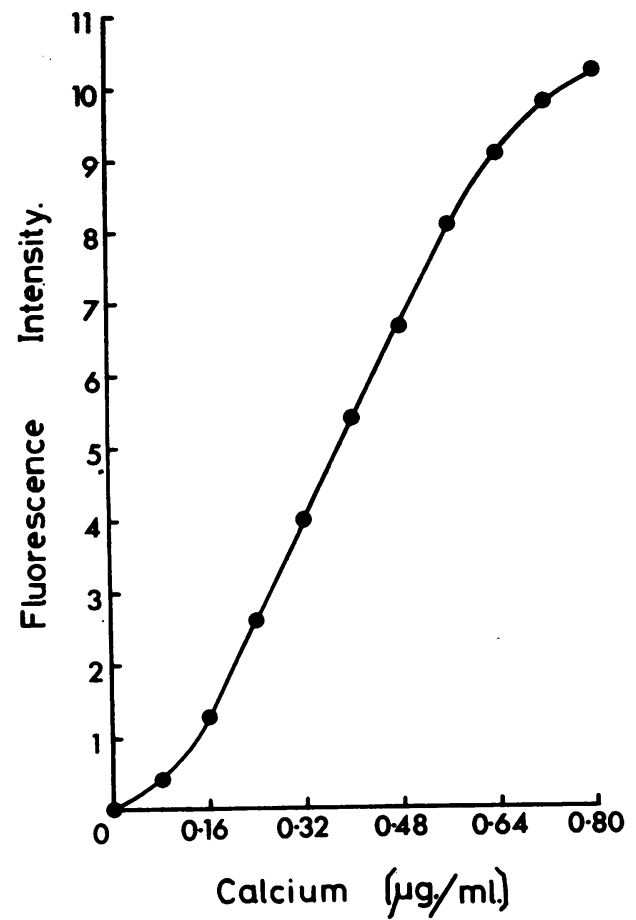

FIG. 1. Calibration curve of standard calcium solutions between absolute concentrations of 0 to $0.80 \mu \mathrm{g} / \mathrm{ml}(0$ to 20 $\mathrm{mg} \mathrm{Ca} / 100 \mathrm{ml}$ ). At a calcein concentration of $8 \mathrm{mg} / \mathrm{l}$., the curve is linear between concentrations of 0.16 to $0.56 \mu \mathrm{g} / \mathrm{ml}$ (4-14 mg Ca/100 ml).

temperature changes during sample mixing, transfer to cuvettes, and reading.

EFFECT OF TIME The fluorescent complex retained its initial fluorescence for at least $\mathbf{1 5}$ minutes when read in a silica cuvette, or stored in a polystyrene tube. When glass cuvettes were used, fluorescence was observed to fade, and was presumably due to the adsorption of calcium on to glass.

EFFECT OF INTERFERING SUBSTANCES The possible interference of magnesium, phosphate, and citrate was investigated by adding solutions of magnesium chloride, dipotassium hydrogen phosphate, and citric acid, to give final concentrations equivalent to one hundred times physiological levels. No interference was demonstrated.

Bilirubin and haemoglobin were shown to have a quenching effect on fluorescence at concentrations of haemoglobin exceeding $500 \mathrm{mg} / 100 \mathrm{ml}$ and of bilirubin exceeding $10 \mathrm{mg} / 100 \mathrm{ml}$.

The presence of EDTA in concentrations exceeding $5 \mathrm{mg} / 100 \mathrm{ml}$ was found to reduce the fluorescence of standard calcium solutions, the calcium-EDTA complex being non-fluorescent.

Human plasma proteins, at concentrations equivalent to three times the normal physiological level, had no effect on the fluorescence of standard calcium solutions. 


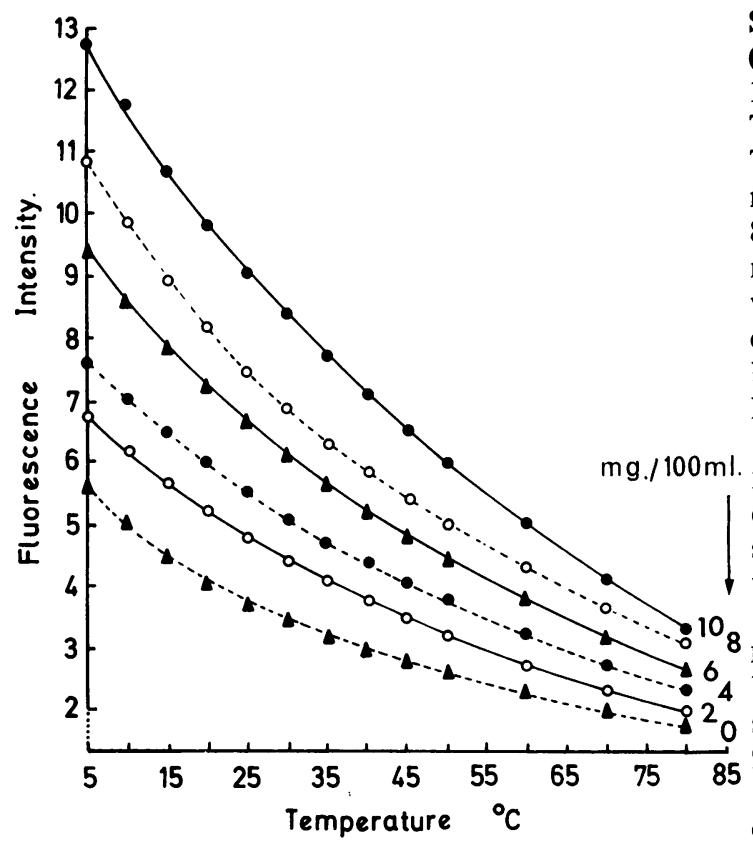

FIG. 2. Effect of temperature on fluorescence of standard calcium solutions at concentrations of $0,2,4,6,8$, and $10 \mathrm{mg} / 100 \mathrm{ml}$.

EFFECT OF GLASSWARE It was found that if glass containers were used either to store solutions or in the method, variations and irregularity in calibration curves were observed. This was overcome by the use of polythene containers for storage and disposable polystyrene tubes for preparing the fluorescent complex. It was presumed that the irregularities experienced using glassware were due to the adsorption of calcium onto glass. While the work on this method was in progress a similar effect of calcium adsorption onto glass was reported by Phillips and Elevitch (1966).

\section{RESULTS}

NORMAL VALUES Blood was collected, without venous stasis, from 100 ambulant normal subjects, aged between 18 and 73 , comprising mainly medical students and members of the laboratory staff. Plasma calcium was estimated using the method described. The specific gravity of each sample was determined by the copper sulphate method of Phillips, van

Slyke, Dole, Emerson, Hamilton, and Archibalळ (1945); plasma calcium was corrected to a SG of: 1.0270 using the factor proposed by Dent (1962) The values for the subjects studied are detailed in Table I. The mean for the whole group was $9 \cdot 6 \bar{Q}$. $\mathrm{mg} / 100 \mathrm{ml}$ with a normal range (mean $\pm 2 \mathrm{SD}$ ) of 8.9 to $10.4 \mathrm{mg} / 100 \mathrm{ml}$. The table also shows that the mean level of plasma calcium in this normal series was not altered by the application of the protein correction factor. A sex distribution is also shown; but the difference between male and female meaß levels of calcium is not significant $(t=1 \cdot 45, P>0 \cdot 1)$

PRECISION The precision of the method was calin culated from 20 replicate estimations performed on a single plasma sample. The coefficient of variation was found to be $0.57 \%$.

RECOVERY The recovery of the method was checked by adding calcium to both the standard calciur solutions and plasma. The results varied betwee $98.6 \%$ and $104.3 \%$.

OXALATE PRECIPITATION We have accepted as $\mathfrak{Q}$ standard method for comparison the Clark an Collip (1925) technique. The results of specimen estimated by both techniques are shown in Table IE The higher values of the Clark and Collip estimations probably result from the coprecipitation of mag nesium during oxalate precipitation (Tingey, 1933)

ANALYSIS OF URINE Application of this fluorimetrie technique to the measurement of urinary calciurt

TABLE II

COMPARISON OF PRESENT METHOD AND OF METHOD OE CLARK AND COLLIP

Method (Uncorrected Ca mg/100 ml)

\begin{tabular}{|c|c|c|}
\hline \multirow[b]{2}{*}{ Sample } & \\
\hline & Present & Clark and Collip (192 \\
\hline 1 & $9 \cdot 7$ & $9 \cdot 8$ \\
\hline 2 & 10.0 & $10 \cdot 1$ \\
\hline 3 & $10 \cdot 2$ & $10 \cdot 4$ \\
\hline 4 & $10 \cdot 3$ & $10 \cdot 3$ \\
\hline 5 & 9.9 & $9 \cdot 7$ \\
\hline 6 & $8 \cdot 7$ & 8.8 \\
\hline 7 & $9 \cdot 9$ & $9 \cdot 8$ \\
\hline 8 & $10 \cdot 3$ & $10 \cdot 3$ \\
\hline 9 & 11.0 & $11 \cdot 2$ \\
\hline 10 & $14 \cdot 3$ & $14 \cdot 6$ \\
\hline 11 & $9 \cdot 6$ & $9 \cdot 6$ \\
\hline 12 & $8 \cdot 8$ & $8 \cdot 8$ \\
\hline
\end{tabular}

TABLE I

NORMAL VALUES IN SUBJECTS STUDIED

\begin{tabular}{|c|c|c|c|c|}
\hline Subject & Age Range (yr) & No. of Subjects & $\begin{array}{l}\text { Mean Determined } \\
\mathrm{Ca}(\mathrm{mg} / 100 \mathrm{ml} \pm S D)\end{array}$ & $\begin{array}{l}\text { Mean Corrected } \\
\mathrm{Ca}(\mathrm{mg} / \mathrm{l0Oml} \pm S D)\end{array}$ \\
\hline $\begin{array}{l}\text { Total } \\
\text { Total men } \\
\text { Total women }\end{array}$ & $\begin{array}{l}18-73 \\
19-58 \\
18-73\end{array}$ & $\begin{array}{r}100 \\
44 \\
56\end{array}$ & $\begin{array}{l}9.66 \pm 0.35 \\
9.73 \pm 0.35 \\
9.61 \pm 0.34\end{array}$ & $\begin{array}{l}9.66 \pm 0.36 \\
9.71 \pm 0.33 \\
9.61 \pm 0.36\end{array}$ \\
\hline
\end{tabular}


has met with varied success, and until fully investigated, it is not recommended.

\section{DISCUSSION}

We have modified the original technique of Kepner and Hercules (1963) by the use of different wavelengths, both for excitation and emission, alteration in the final calcein concentration, temperature control, elimination of glassware from the procedure, and by reduction in the number of pipetting stages. With these modifications, this method has proved to be rapid, accurate, and precise. The normal range of plasma calcium as determined by us fluorimetri-

TABLE III

\begin{tabular}{|c|c|c|}
\hline \multirow[b]{2}{*}{ Method } & \multicolumn{2}{|c|}{ RANGES OF PLASMA CALCIUM } \\
\hline & $\begin{array}{l}\text { Range of Plasma } \\
\text { Calcium } \\
(\mathrm{mg} / 100 \mathrm{ml})\end{array}$ & Reference \\
\hline $\begin{array}{l}\text { Flame photometry } \\
\text { Atomic absorption }\end{array}$ & $9 \cdot 5-11 \cdot 5$ & MacIntyre (1961) \\
\hline $\begin{array}{l}\text { spectrophotometry } \\
\text { EDTA titration } \\
\text { Fluorimetry }\end{array}$ & $\begin{array}{l}8 \cdot 4-10 \cdot 1 \\
8 \cdot 8-10 \cdot 4 \\
8 \cdot 9-10 \cdot 4\end{array}$ & $\begin{array}{l}\text { Thin \& Thomson (1967) } \\
\text { Nordin \& Smith (1965) } \\
\text { Present method }\end{array}$ \\
\hline
\end{tabular}

cally is similar to normal ranges taken from the literature (Table III).

We wish to thank the Endowment Fund of the Royal Free Hospital for support.

\section{REFERENCES}

Bachra, B. N., Dauer, A., and Sobel, A. E. (1958). Clin. Chem., 4, 107. Baron, D. N., and Bell, J. L. (1957). Clin. chim. Acta, 2, 327.

Butterworth, E. C. (1957). J. clin. Path., 10, 379.

Carubelli, R., Smith, W. O., and Hammarsten, J. F. (1959). Clin. Chem., 5, 45.

Clark, E. P., and Collip, J. B. (1925). J. biol. Chem., 63, 461.

Dent, C. E. (1962). Brit. med. J., 2, 1419.

Kepner, B. L., and Hercules, D. M. (1963). Analyt. Chem., 35, 1238.

MacIntyre, I. (1961). Advanc. clin. Chem., 4, 1.

Nordin, B. E. C., and Smith, D. A. (1965). Diagnostic Procedures in Disorders of Calcium Metabolism. Churchill, London.

Phillips, R. A., van Slyke, D. D., Dole, V. P.,Emerson, K. Jr, Hamilton, P. B., and Archibald, R. M. (1950). Copper Sulfate Method for Measuring Specific Gravities of Whole Blood and Plasma. Rev. ed. Josiah Macey, Jr Foundation (For U.S. Navy Res. Unit, Hosp. of Rockefeller Inst. for Med. Res.), New York.

Phillips, R. E., and Elevitch, F. R. (1966). Progr. clin. Path., 1, 62 .

Schwarzenbach, G., and Gysling, H. (1949). Helv. chim. Acta, 32, 1314.

Thin, C. G., and Thomson, P. A. (1967). J. clin. Path., 20, 280.

Tingey, A. H. (1933). Biochem. J., 27, 332.

Wallach, D. F. H., and Steck, T. L. (1963). Analyt. Chem., 35, 1035.

Williams, R. T., and Bridges, J. W. (1964). J. clin. Path., 17, 371. 